\title{
Effect of Bamboo Powder Supplementation on Physicochemical and Organoleptic Characteristics of Fortified Cookies
}

\author{
Umair Mustafa, Naureen Naeem*, Saima Masood, Zubair Farooq \\ Department of Food Science and Human Nutrition, University of Veterinary and Animal Sciences, Pakistan
}

Copyright (C) 2016 by authors, all rights reserved. Authors agree that this article remains permanently open access under the terms of the Creative Commons Attribution License 4.0 International License

\begin{abstract}
Present study focused on the use of bamboo shoots powder for the production of baked goods owing to their enormous health benefits. It was an endeavor to make use of cheaper sources through high nutritional contour for the production of best quality baked products. Proximate composition revealed that the powder of bamboo shoots contained elevated amount of fiber $(24.44 \%)$ and protein contents (19.32\%) while the lowest amount of fats $(1.46 \%)$. Similarly means values for $\mathrm{T}_{10}$ was found to contain $14.10 \%$ protein and $2.48 \%$ fiber followed by mean values for $\mathrm{T}_{8}$ with $13.97 \%$ protein and $1.97 \%$ fiber, while means for fat percentage were non-significantly different among all treatments. Physical characteristics like diameter, thickness and spread factor were affected significantly in all treatments. Significant reduction in the spread factor of the cookies was observed with increase in bamboo shoot powder. As low-cost and readily available source bamboo shoots offers an exciting new potential substance as a food ingredient especially in cookies. Physical characteristics depicted exceptional dough making characteristics when mixed with wheat flour. In this investigation sensory evaluation shows that the cookies prepared from $6 \%$ and lower level of the bamboo shoots fortified flour were acceptable.
\end{abstract}

Keywords Bamboo Shoots, Dietary Fiber, Cookies

\section{Introduction}

Bamboos belonging to the family Poaceae, are generally known for their industrial uses. They are plants of universal interest because of their unique life form, ecological importance, and the wide range of uses and values they have for humans. Today, it helps more than 2 billion people meet their basic needs and as a widespread, renewable, productive, versatile, low- or no-cost, easily accessed, environment-enhancing resource; it has great potential to improve life, especially in the rural areas of the developing world [1]. Bamboos are gaining increased attention as an alternative crop with multiple uses and benefits, providing human beings with various living resources. They are intermixed with the tradition and culture of rural and tribal populations and are an integral part of their cultural, social, and economic conditions [2,3].Bamboo shoots are not only delicious but are rich in nutrient components, mainly proteins, carbohydrates, minerals, and fiber and are low in fat and sugars. In addition, they contain phytosterols and a high amount of fiber that can be labeled as nutraceuticals or natural medicines that are attracting the attention of health advocates and scientists alike. The shoots are free from residual toxicity and grow without the application of fertilizers. Modern research has revealed that bamboo shoots have a number of health benefits: improving appetite and digestion, weight loss, and curing cardiovascular diseases and cancer. The shoots are reported to have anticancer, antibacterial, and antiviral activity. Shoots have antioxidant capacity due to the presence of phenolic compounds. The increasing trends of health consciousness among consumers have stimulated the field of functional foods and bamboo shoots can be one of them. Bamboo fiber is now a common ingredient in breakfast cereals, fruit juices, bakery and meat products, sauces, shredded cheeses, cookies, pastas, snacks, frozen desserts, and many other food products. .[4] In this era, modern agricultural system is at crossroads due to stagnant productivity[5]. In this situation people's attention is being diverted towards non -timber forest products (NTFPs) like bamboos. These are products of biological origin (other than wood) derived from forests. [6]. More than 1250 species having a place with 75 genera have been accounted for to be born worldwide [7]. Out of which 25 species are found in Pakistan. [8].

Latest advancement proves the bamboo shoot as a functional food due to the presence of biochemical components like dietary fiber, polyphenols and sterols. A lot of evidences are found for the uses of bamboo shoots in 
Ayurvadic medicines. Ayurveda medicine uses the ash of bamboo shoots against different diseases in India [8]. They are found to contain great potential as a food resource. Consumption of bamboo shoots is mainly concentrated in Southeast Asia, where they are a popular ingredient in the local cuisine. From earlier times, young edible bamboo shoots have remained one of the highly palatable dishes in China, Taiwan, Japan and Korea. [8].

In South Asian countries, bamboos have been utilized for traditional medicine treatments to relieve hypertension, sweating, and paralysis. Modern research shows that the bamboo shoots have many health benefits, from cancer prevention and weight loss to lowering cholesterol level and improving appetite and digestion. It has low glycemic index therefore can be used by persons on sugar-restricted diets. The shoots also contain anticarcinogenic agents, which when consumed as a regular part of diet effectively reduces the free radicals that can produce harmful carcinogens. Some studies show that bamboo extract may have antioxidant activities and provide anti-inflammatory effects [7,8]. Furthermore, bamboo-derived functional bio-components like pyrolysates have been proposed to have antimicrobial and antifungal activities $[7,8]$.

Diet plays a pivotal role to maintain the functions of human body as well as fulfilling the basic requirements of hunger. Demand for high quality food products is increasing day by day. New technologies and ingredients are introduced in the world for fulfilling the nutritional needs. Now modern world is turning towards functional foods from drugs. Functional foods provide the strength and can cut the risk of diseases beyond providing basic nutrition, including maintenance of gut health [9]. The usage of functional foods increased, as well as awareness is advanced. Functional foods not only provide nutrition but work as defense against human nutrition related diseases. Worldwide market of functional foods business has worth at least 33 billion [10].

Bamboo shoots are a rich source of dietary fiber [10,11]. They have high amounts of fiber, ranging from 2.23 to 4.20 $\mathrm{g} / 100 \mathrm{~g}$ fresh weight of shoot in some bamboo species. As a dietary fiber source, the shoots have beneficial effects on lipid profile and bowel function. Studies conducted by [11] have confirmed the beneficial effects of consuming a high-fiber diet containing bamboo shoots in lowering blood cholesterol levels and improving bowel functions in healthy young women. Supplementing the diet with bamboo shoots was associated with reductions in total and LDL cholesterol levels in 8 young women. Dietary fiber is an essential part of human's diet specially known due to functional food. Dietary fiber incorporates polysaccharides, oligosaccharides, lignin and associated plant substances [11]. Generally, there are two types of dietary fiber, soluble and insoluble. Classification of dietary fiber based on solubility in water, viscosity and microbial fermentation in the large intestine. Soluble dietary fibers include gums, pectin and polysaccharides, whereas insoluble DFs include lignin cellulose, hemicellulose. [12]. Barley bran, psyllium and oat bran, mostly soluble fiber, and are well known for their ability to lower blood lipid level. Some insoluble fibers and wheat bran are typically linked to laxation, whereas soluble fibers lower blood cholesterol is inconsistent at best [13].

Dietary fiber can be partially or completely fermented to short chain fatty acids (SCFA), propionate, acetate and butyrate [14]. The patterns of fermentation and the ratio of SCFAs produced depend on DF type. The main product of pectin fermentation is acetate whereas fermentation of cylcodextrins and gum arabic results primarily in propionate [15]. As a final point the physiological effects of DF due to the type and amount of SCFAs produced and the ability of these SCFAs to stimulate sodium absorption, intestinal water as well as influence gut $\mathrm{pH}$ and bile salt precipitation [16].The properties of popular baked foods have been studied to a limited extent. Very little of the work done in the research conducted on rheological properties and baking performances of dough's that contain added soluble fiber [17]. The effects of popular baked foods like cookies to deliver functional dietary fiber are studied to a limited extent [18]. The key advantages of using dried bamboo shoot powder is its low moisture content which may allow its direct use into various dry food items, and preparing chutney and beverages. Other advantages of using dried bamboo shoot based powder may include free-flowing, ease of handling and weighing, reduced storage space, ease of cleaning and sanitary aspects. In Japan, bamboo shoot-based powder is used as an essence in cookies and various other food items. Japanese use bamboo powder in standard bread flour and also recommends a 3-8\% addition of the powder to any food products [11]. In China, bamboo juice produced by pressure-cooking, is used to make beverages and specific liquors, apart from medicines [18]. With a characteristic bamboo aroma and beer flavor, bamboo juice beers show a good number of health benefits by lowering blood lipids and fighting heart ailments[18].

\section{Materials and Methods}

\section{Procurement of Raw Materials}

In this investigation the specie of bamboo shoots were used brought from local fields of Qasoor district. The wheat fine flour and other material like sugar, oil, salt and baking powder were procured from local market.

\section{Preparation of Bamboo Shoots Powder}

Shoots were collected and packed in polythene bag followed by peeling and chopping into small pieces with the help of knife. The fresh shoots have glycocyanide contents. The consumption of glycocyanide contents is harmful for human's health. Pieces of shoots were boiled (3-4 hours) for the removal of glycocyanide contents at $100^{\circ} \mathrm{C}$. The shoots were dried in hot air oven (Model: Beschikun Loading Modell $100-800$ ) at $70^{\circ} \mathrm{C}$ for 24 hours till its weight become constant. The dried shoots were grinded for the preparation of powder. 


\section{Preparation of Composite Flour and Treatments}

Composite flour was prepared by mixing of bamboo shoots powder and fine flour. The bamboo shoots powder was mixed with fine wheat flour and six treatments were prepared in which one treatment was control and five treatments were mixed at different ratios as given below.

Table 1. Formulations of different addition ratios of Bamboo shoots powder to wheat flour

\begin{tabular}{|c|c|c|}
\hline Treatments & Fine Flour $\%$ & Bamboo Shoots Powder \% \\
\hline $\mathrm{T}_{0}$ & 100 & 0 \\
\hline $\mathrm{T}_{2}$ & 98 & 2 \\
\hline $\mathrm{T}_{4}$ & 96 & 4 \\
\hline $\mathrm{T}_{6}$ & 94 & 6 \\
\hline $\mathrm{T}_{8}$ & 92 & 8 \\
\hline $\mathrm{T}_{10}$ & 90 & 10 \\
\hline
\end{tabular}

* $\mathbf{T}_{\mathbf{0}}$ act as control

\section{Proximate Analysis of Composite Flour treatments}

The resultant fortified flour was analyzed for moisture content, crude protein (Method no. 46-30), ash content (Method no.08-01), crude fat (Method no. 30-25), crude fiber (Method no. 32-10) and nitrogen free extract (NFE) according to their respective procedures mentioned in [19].

\section{Preparation of Cookies}

Cookies were prepared from the fortified flour treatments accordingly. The ingredients were added as per sequence in Hobart Mixer and the substances were mixed to a homogeneous mass. The batter were rolled and cut with a 50$\mathrm{mm}$ diameter cookie cutter. The cookies were baked at $160^{\circ} \mathrm{C}$ for $30-36 \mathrm{~min}$ and cooled at ambient temperature. The cookies were packed in tin boxes and were kept at room temperature prior to further analysis.

\section{Physical Analysis of Cookies}

The diameter (D), thickness (T) and spread factor of the cookies prepared from control and treatment samples were measured and calculated according to their corresponding protocols described in [19].

\section{Proximate Analysis of Cookies}

The proximate analysis of cookies prepared with different treatments included dry matter, crude protein (Method no. 46-30), crude fat (Method no. 30-25), crude fiber (Method no. 32-10), ash content (Method no.08-01) and nitrogen free extract (NFE) determination according to their respective procedures [19].

\section{Sensory Evaluation}

The sensory evaluation of cookies was done by untrained panel of 20 judges on 9 point hedonic scale. A Performa of this scale was given to judges on whom different attributes like appearance, taste, aroma, flavor, texture, crispness and over all acceptability are mentioned. All evaluations were conducted at room temperature under white lights in the Department of Food Science and Human Nutrition. Cookies were presented in small plates, labeled with three digits English alphabets. The cookie samples were presented in random order and panelists were asked to rate their acceptance for color, aroma, taste, appearance, texture, crispiness, and overall acceptability. Nestle pure water was provided to judges for rinse between evaluation. A score of 5 or above were considered a limit of acceptability for all sensory attributes tested.

\section{Statistical Analysis}

The data thus obtained were analyzed by applying completely randomized design (CRD) and the results were analyzed through analysis of variance technique [19] using SPSS version 16.0 to determine the level of significance. The separation of means or significant difference contrasts was done by Duncan multiple range test. The numerical consequence was well-defined as $P \leq 0.05$.

\section{Results and Discussion}

The proximate composition of fresh bamboo shoots, bamboo shoots powder and wheat fine flour presented in table 2. Proximate composition showed higher amount of protein and fiber in powder of bamboo shoots as compared to fine flour. On the other hand wheat fine flour has very minute amount of dietary fiber and maximum amount of nitrogen free extract. Bamboo shoots is the richest source of dietary fiber and great amount of protein [20].

Table 2. Means for proximate composition

\begin{tabular}{|c|c|c|c|}
\hline Parameters & Fresh Bamboo shoots & Bamboo shoots powder & Wheat Fine flour \\
\hline Moisture & $85.65 \pm 2.37$ & $13.62 \pm 2.25$ & $11.90 \pm 0.10$ \\
\hline Fiber & $3.90 \pm 0.27$ & $24.44 \pm 2.45$ & $0.30 \pm 0.01$ \\
\hline Protein & $3.72 \pm 0.32$ & $19.32 \pm 2.31$ & $12.90 \pm 1.20$ \\
\hline NFE & $5.50 \pm 0.23$ & $37.00 \pm 1.26$ & $71.80 \pm 0.29$ \\
\hline Fat & $0.40 \pm 0.02$ & $1.46 \pm 0.03$ & $1.80 \pm 0.01$ \\
\hline Ash & $0.83 \pm 0.04$ & $4.16 \pm 0.07$ & $1.30 \pm 0.02$ \\
\hline
\end{tabular}

Proximate composition of control T2, T4, T6, T8 and T10 treatments presented in table 3. Fiber, Protein, NFE, Fat and Ash contents increase with the increases of bamboo shoots powder while the moisture contents decreased with the increases of bamboo shoots powder. 
Table 3. Means for proximate analysis of bamboo shoots supplemented flour

\begin{tabular}{|c|c|c|c|c|c|c|}
\hline Parameters & $\mathbf{T}_{\mathbf{0}}$ & $\mathbf{T}_{\mathbf{2}}$ & $\mathbf{T}_{\mathbf{4}}$ & $\mathbf{T}_{\mathbf{6}}$ & $\mathbf{T}_{\mathbf{8}}$ & $\mathbf{T}_{\mathbf{1 0}}$ \\
\hline Moisture & $11.90 \pm 1.36 \mathrm{a}$ & $11.76 \pm 1.11 \mathrm{ab}$ & $11.60 \pm 1.21 \mathrm{~b}$ & $11.67 \pm 1.32 \mathrm{bc}$ & $11.58 \pm 1.38 \mathrm{c}$ & $11.40 \pm 1.28 \mathrm{c}$ \\
\hline Fiber & $0.30 \pm 0.01 \mathrm{f}$ & $0.56 \pm 0.02 \mathrm{e}$ & $0.99 \pm 0.02 \mathrm{~d}$ & $1.48 \pm 0.03 \mathrm{c}$ & $1.97 \pm 0.04 \mathrm{~b}$ & $2.48 \pm 0.09 \mathrm{a}$ \\
\hline Protein & $12.90 \pm 1.27 \mathrm{e}$ & $13.30 \pm 1.37 \mathrm{~d}$ & $13.80 \pm 1.19 \mathrm{c}$ & $13.90 \pm 1.21 \mathrm{c}$ & $13.97 \pm 1.27 \mathrm{ab}$ & $14.10 \pm 1.34 \mathrm{a}$ \\
\hline NFE & $71.80 \pm 3.41 \mathrm{a}$ & $71.10 \pm 3.25 \mathrm{~b}$ & $70.30 \pm 3.17 \mathrm{~b}$ & $69.60 \pm 2.98 \mathrm{bc}$ & $69.10 \pm 2.87 \mathrm{c}$ & $68.60 \pm 3.18 \mathrm{~d}$ \\
\hline Fat & $1.80 \pm 0.03 \mathrm{~b}$ & $1.83 \pm 0.06 \mathrm{ab}$ & $1.84 \pm 0.04 \mathrm{ab}$ & $1.86 \pm 0.03 \mathrm{a}$ & $1.87 \pm 0.02 \mathrm{a}$ & $1.89 \pm 0.05 \mathrm{a}$ \\
\hline Ash & $1.30 \pm 0.02 \mathrm{e}$ & $1.45 \pm 0.04 \mathrm{~d}$ & $1.47 \pm 0.03 \mathrm{c}$ & $1.49 \pm 0.05 \mathrm{~b}$ & $1.51 \pm 0.03 \mathrm{a}$ & $1.53 \pm 0.06 \mathrm{a}$ \\
\hline
\end{tabular}

Means sharing the same letter in a row are not significantlydifferent.

Table 4. Physical characteristics of bamboo shoots fortified cookies

\begin{tabular}{|c|c|c|c|}
\hline Treatments & Diameter $\mathbf{( c m )}$ & Thickness $(\mathbf{c m})$ & Spread factor \\
\hline $\mathbf{T}_{\mathbf{0}}$ & $5.98 \pm 0.02 \mathrm{a}$ & $1.36 \pm 0.03 \mathrm{c}$ & $45.34 \pm 0.56 \mathrm{a}$ \\
\hline $\mathbf{T}_{\mathbf{2}}$ & $5.97 \pm 0.03 \mathrm{a}$ & $1.35 \pm 0.02 \mathrm{a}$ & $43.93 \pm 0.33 \mathrm{~b}$ \\
\hline $\mathbf{T}_{\mathbf{4}}$ & $5.91 \pm 0.07 \mathrm{~b}$ & $1.35 \pm 0.04 \mathrm{~b}$ & $43.66 \pm 0.28 \mathrm{~b}$ \\
\hline $\mathbf{T}_{\mathbf{6}}$ & $5.83 \pm 0.06 \mathrm{~b}$ & $1.33 \pm 0.02 \mathrm{~b}$ & $43.72 \pm 0.34 \mathrm{a}$ \\
\hline $\mathbf{T}_{\mathbf{8}}$ & $5.76 \pm 0.05 \mathrm{c}$ & $1.34 \pm 0.05 \mathrm{~b}$ & $42.67 \pm 0.28 \mathrm{~b}$ \\
\hline $\mathbf{T}_{\mathbf{1 0}}$ & $5.68 \pm 0.04 \mathrm{~d}$ & $1.32 \pm 0.03 \mathrm{c}$ & $41.88 \pm 0.45 \mathrm{c}$ \\
\hline
\end{tabular}

Means sharing the same letter in a column are not significantly different.

Results for the thickness of cookies revealed that the cookies prepared from the composite flour containing bamboo shoots powder varied significantly between different treatments. Cookies thickness gradually decreased as the level of bamboo shoots powder increased. Data according to the mean values of the cookies thickness (Figure 1) showed the highest value $(1.36 \mathrm{~cm})$ was found in $\mathrm{T}_{0}$ on the other hand the lowest value $(1.32 \pm 0.03)$ for thickness was found in $T_{10}$.

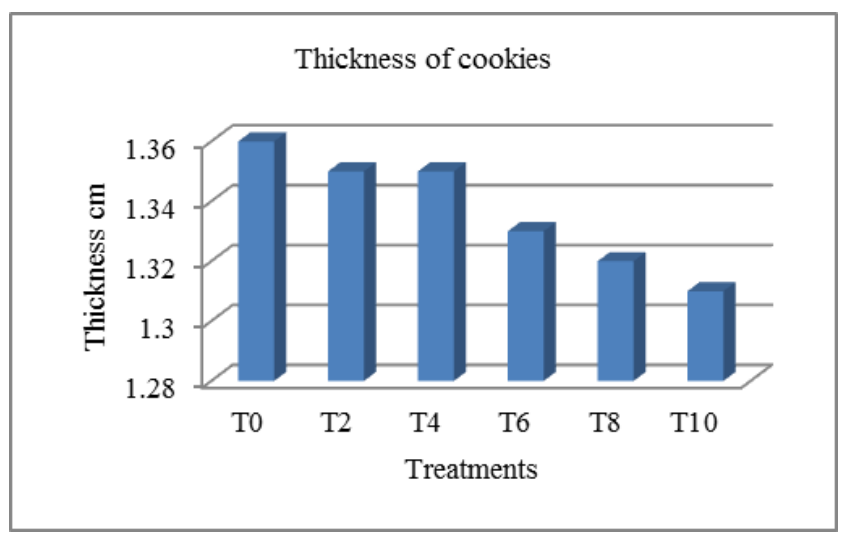

Figure 1. Thickness of cookies in different treatments of composite flour
The mean values for the diameter of cookies (Figure 2) prepared from the different treatments of the composite flour disclosed that the highest significant value $(5.98 \pm 0.02)$ was seen for those cookies prepared from control treatment. The diameter of cookies decreased as well as the amount of bamboo shoots powder increased. Lowest value $(5.68 \pm 0.04)$ was observed for T10 treatment cookies.

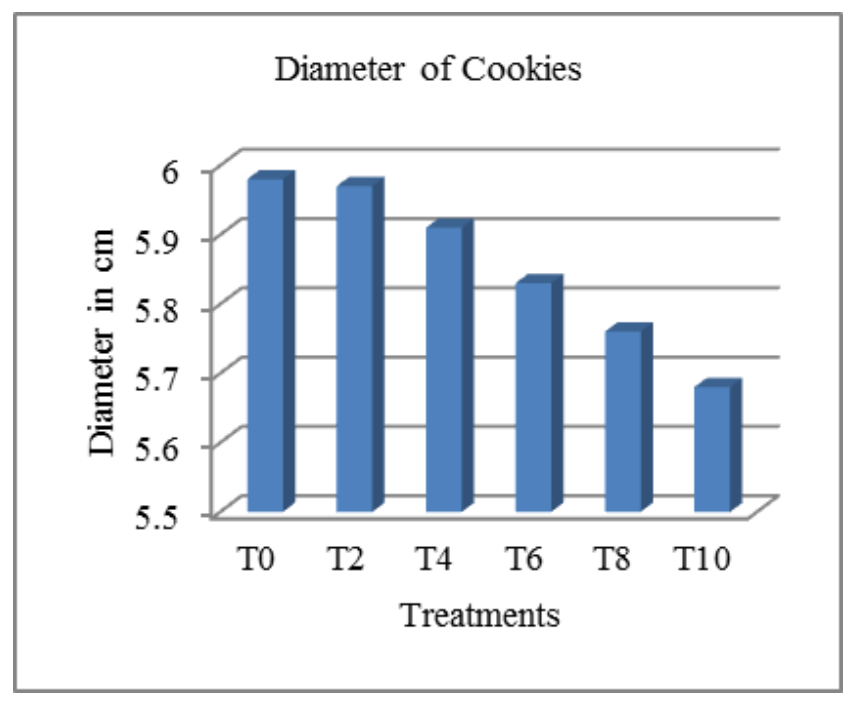

Figure 2. Diameter of the cookies of different treatments 


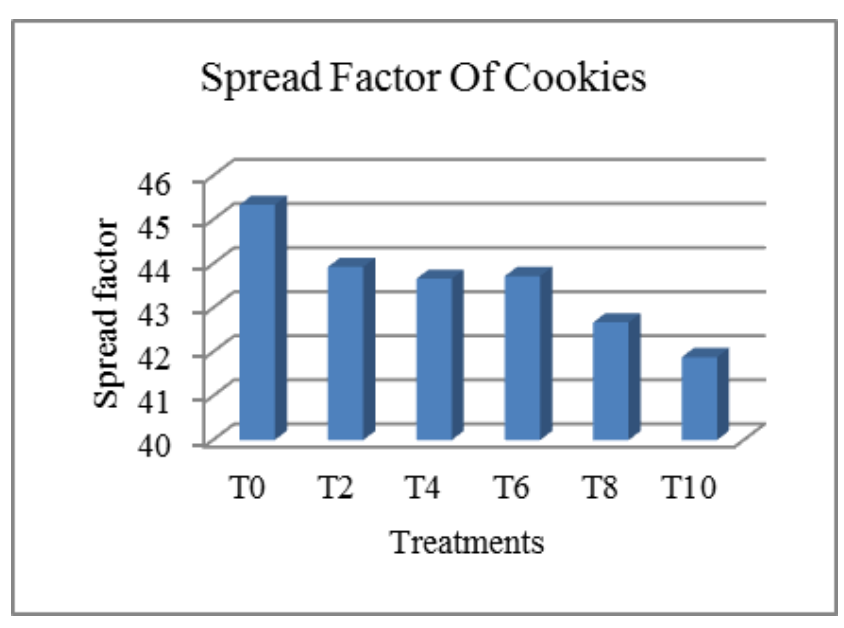

Figure 3. Spread Factor of the cookies of different treatments

Mean squares for various physical parameters of bamboo shoots fortified cookies given in Table 4.

Physical characteristics of different cookies are given in Table 4. The values for diameter of cookies showed the control treatment have maximum diameter while the diameter decreased as well as the fortification of bamboo shoots powder increases.

\section{Organoleptic Evaluation of Cookies Prepared from Bamboo Shoots Composite Flour}

The preliminary evaluation by a small panel showed that, except for overall acceptability, no differences were found in all other sensory attributes up to $10 \%$ bamboo shoot flour level. Flour blends containing $8 \%$ and $10 \%$ BS flour produced cookies with significantly lower scores for all sensory attributes. Consumer panel sensory scores of cookie color were not significantly different from the control (Table 5). Consumer acceptance regarding aroma, taste and overall acceptability was significantly $(\mathrm{P}<0.05)$ higher for cookies prepared from control and 5\% bamboo shoot composite flour as compared with $10 \%$ and $15 \%$ bamboo shoot flour fortification. As the level of bamboo shoot flour fortification increased, the scores for cookie crispiness decreased accordingly. In sensory evaluation of cookies color is very important parameter in the judgment of properly baked cookies which not only reflects appropriate raw material used for the preparation but also gives the information concerning the formulation and quality of the products. Scores for the quality of colors were given in Table 5. The results showed highest score was scored by cookies prepared from $\mathrm{T}_{0}$. On the other hand the lowest score was scored the cookies prepared from $\mathrm{T}_{10}$ treatment. Judges have disliked the cookies prepared from $T_{8}$ and $T_{10}$ regarding color when subjected under sensory evaluation. As the level of supplementation of bamboo shoots powder increased, the color of cookies observed darker. It is may be due to darker color of bamboo shoots powder. Flavor plays the pivotal role in the likeness or unlikeness of the product. The quality score results revealed the flavor of cookies have significant variation between different treatments. The results showed the cookies prepared from control treatment achieved highest score (7.90) regarding flavor. Judges accepted the cookies regarding flavor prepared from all the treatments composite flour having bamboo shoots powder. Taste is the major factor in the acceptance of newly produced products. The results indicated the cookies prepared from $\mathrm{T}_{0}$ got highest scores (7.85) while the lowest score was observed the cookies prepared from $T_{8}$ and $T_{10}$. This may be due to high level of bamboo shoots powder. Quality score for the crispness of cookies was represented in Table 5. The observations according to crispness quality scores showed ranged from 6.87 to 7.98 . The highest quality score was got the treatment prepared from $\mathrm{T} 0$ while the lowest score was found the treatment prepared from $T_{10}$. Judges have accepted all the cookies prepared from different treatments of composite flour regarding crispness. Texture of the cookies containing bamboo shoots powder in their formulation was significantly affected with the increase in the level of bamboo shoots powder. Cookies prepared from the treatment $T_{10}$ got the lowest scores 5.99 while the treatment $T_{0}$ achieved highest scores 8.39. Judges accepted all the cookies prepared from different treatments of composite flour with respect to texture. The results regarding overall acceptability of different cookies depicted in Table (5). Results regarding overall acceptability revealed the fortification significantly affected the different treatments of composite flour. Highest score (8.95) was obtained the cookies prepared from $\mathrm{T}_{0}$. On the other hand the lowest score got the cookies prepared from the $T_{10}$ treatment. Judges have accepted all the cookies prepared from different treatments of composite flour regarding overall acceptability. The results for the sensory attributes of cookies prepared from the various treatments are according to the findings of Younus et al. [20], Sudha et al. [21] and Sharma et al. [22] who reported the increasing level of different high fiber products composite flour resulted in the significant decrease in the sensory attributes of cookies. 
Table 5. Organoleptic attributes of the cookies containing bamboo shoots composite flour

\begin{tabular}{|c|c|c|c|c|c|c|}
\hline Treatments & Color & Flavor & Taste & Crispness & Texture & Overall Acceptability \\
\hline $\mathrm{T}_{0}$ & $6.29 \mathrm{c}$ & $6.64 \mathrm{c}$ & $5.28 \mathrm{~d}$ & $7.60 \mathrm{a}$ & $6.07 \mathrm{~d}$ & $8.11 \mathrm{~b}$ \\
\hline $\mathrm{T}_{2}$ & $6.38 \mathrm{c}$ & $7.60 \mathrm{~b}$ & $5.70 \mathrm{c}$ & $7.67 \mathrm{a}$ & $5.99 \mathrm{~d}$ & $7.62 \mathrm{c}$ \\
\hline $\mathrm{T}_{4}$ & $8.28 \mathrm{a}$ & $7.90 \mathrm{a}$ & $6.57 \mathrm{~b}$ & $6.87 \mathrm{c}$ & $8.39 \mathrm{a}$ & $8.59 \mathrm{a}$ \\
\hline $\mathrm{T}_{6}$ & $6.90 \mathrm{~b}$ & $6.46 \mathrm{~d}$ & $7.85 \mathrm{a}$ & $7.98 \mathrm{a}$ & $7.17 \mathrm{~b}$ & $8.42 \mathrm{a}$ \\
\hline $\mathrm{T}_{8}$ & $6.54 \mathrm{~b}$ & $6.94 \mathrm{~b}$ & $7.05 \mathrm{a}$ & $6.96 \mathrm{c}$ & $7.54 \mathrm{~b}$ & $7.95 \mathrm{~b}$ \\
\hline $\mathrm{T}_{10}$ & $5.83 \mathrm{~d}$ & $6.33 \mathrm{e}$ & $6.32 \mathrm{~b}$ & $7.16 \mathrm{~b}$ & $6.43 \mathrm{c}$ & $7.55 \mathrm{c}$ \\
\hline
\end{tabular}

\section{Scores for organoleptic evaluation of cookies}

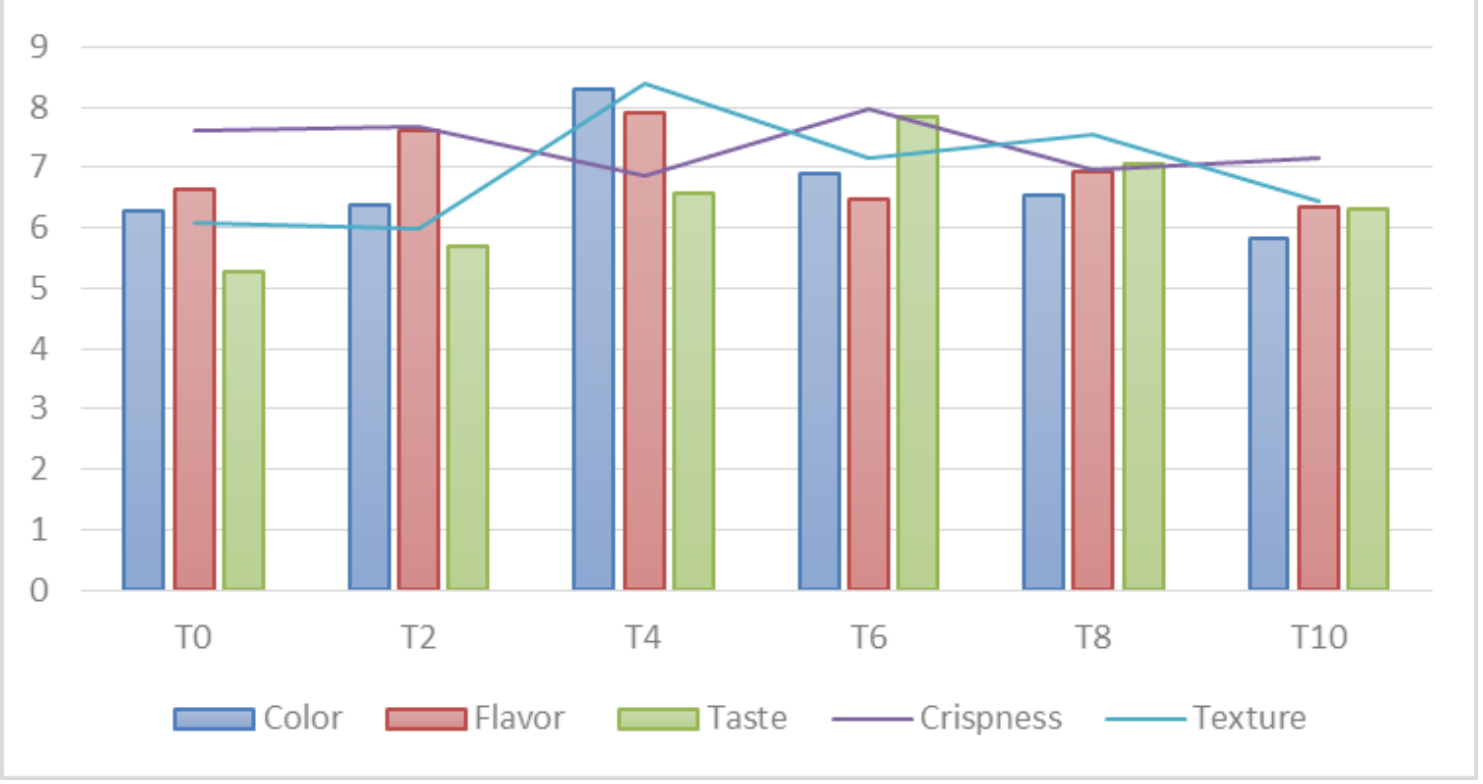

Figure 4. Scores for organoleptic attributes of composite flour cookies

\section{Conclusions}

The present exploration suggested bamboo shoots as an excellent supplemented flour for cookie production. Owing to nutritional composition and readily availability it is established that bamboo shoots can be incorporated in cookies to increase their meticulousness in nutrition conscious consumers. Organoleptic and phsico chemical analysis of fortified wheat flour with bamboo shoot powder revealed that this innovative product can bring a change in the production of functional foods with enhanced accuracy. The current research on this extraordinary material is very fascinating leading to emergence of new avenues of bamboo utilization including baking industry with nutraceutical potential.

\section{REFERENCES}

[1] Sastry CB. A 2020 vision for bamboos in India: Opportunities and challenges. Proceedings of International Conference
"Improvement of Bamboo Productivity and Marketing for Sustainable Livelihood. New Delhi 15-17th April; p 6-15. (2008).

[2] Tewari DN. Bamboo as poverty alleviator. Ind For 114:610-2. (1988).

[3] Madhab J. The green gold: under-exploited wealth of north-east India. Dialogue 5(2):45-52. (2003).

[4] Nirmala C, Sheena H, David E. Bamboo shoots: a rich source of dietary fibres. In: KleinF, MollerG, editors. Dietary fibres, fruit and vegetable consumption and health. USA : Nova Science Publishers. p 15-30.(2009).

[5] Park EJ, Jhon DY. Effects of bamboo shoot consumption on lipid profiles and bowel function in healthy young women. Nutrition 25:723-8. (2009).

[6] Shen, Q. Kong F. and Wang, . "Effect of modified atmosphere packaging on the browning and lignification of bamboo shoots," Journal of Food Engineering, 77(2): 348-354 (2006)

[7] Choudhury,D. and Sharma, G.D. "Biochemistry of Bitterness in Bamboo Shoots. Physical Sciences and Technology," Physical Sciences and Technology, 6(2): 105-111(2010) 
[8] Pandey, A. and Ojha, V. "Precooking processing of bamboo shoots for removal of anti-nutrients," Journal of Food Science and Technology, 51(1): 1-8 (2011)

[9] Bhatt, B.P. Singha L.B. Singh, K. and Sachan, M.S. "Some commercial edible bamboo species of north-east India: production, indigenous uses, cost-benefit and management strategies," Bamboo Science and Culture, 17(1): 4-20 (2003)

[10] Nirmala, C. and David, E." A comparative study of nutrient components of freshly emerged, fermented and canned bamboo shoots of Dendrocalamus giganteus Munro," Journal of American Bamboo Society, 2: 33-39 (2008)

[11] Topping, D.L. "Dietary Fiber: Physiological Effects and Health Outcomes, in Encyclopedia of Human Nutrition (Third Edition), B. Caballero," Editor, Academic Press: Waltham.1 : 50-54 (2013)

[12] Lu, B. Wu, X. Tie, X. and Zhang, Y." Toxicology and safety of antioxidant of bamboo leaves. Part I: acute and subchronic toxicity studies on antioxidant of bamboo leaves," Foodand Chemical Toxicology, 43(5): 783-792 (2005)

[13] Fujimura, M Ideguchi, M. Minami, Y. Watanabe, K. and Tadera, K. "Amino acid sequence and antimicrobial activity of chitin binding peptides, Pp-AMP 1 and Pp-AMP2, from Japanese bamboo shoots (Phyllostachys pubescens)," Bioscience Biotechnology and Biochemistry, 69: 639-645 (2005)

[14] Cencic, A. and Chingwaru, W. "The role of functional foods, nutraceuticals, and food supplements in intestinal health," Nutrients, 2(6): 611-625 (2010)

[15] M, H. "Functional food How big is the market?" The World of Food Ingredients, 12: 50-52 (2000)

[16] AACC, "Dietary Fiber Technical Committee," The definition of dietary fiber. Cereal Foods World, 46: p. 112-126. (2001)

[17] Papathanasopoulos, Athanasios, and Michael Camilleri. "Dietary fiber supplements: effects in obesity and metabolic syndrome and relationship to gastrointestinal functions," Gastroenterology, 38: 65-72 (2010)

[18] Lunn, J. and Buttriss, J.L. "Carbohydrates and dietary fibre," Nutrition Bulletin, 32(1): 21-64 (2007)

[19] AACC. Approved Methods of the American Association of Cereal Chemists. Am. Assoc. Cereal Chem. Inc., St. Paul,
Minnesota.( 2000)

[20] Steel R.G.D. and Torrie, J.H.Principles and Procedures of Statistics, Second Edition, New York: McGraw-Hill Book Co. (1980)

[21] Kaewprasert, Sarunya, Minoru Okada, and Yoritaka Aoyama. "Nutritional effects of cyclodextrins on liver and serum lipids and cecal organic acids in rats," Journal of nutritional science and vitaminology, 47: 335-339 (2001)

[22] Ushida, K. Hatanaka, H. Inoue, R. Tsukahara, T. and Phillips, G.O. "Effect of long term ingestion of gum arabic on the adipose tissues of female mice," Food Hydrocolloids, 25: $1344(2011)$

[23] Pylkas, Anne M. Lekh Raj Juneja, and Joanne, L. Slavin. "Comparison of different fibers for in vitro production of short chain fatty acids by intestinal microflora," Journal of Medicinal Food, 8: 113-116 (2005)

[24] Frost, Diana June, Koushik Adhikari, and Douglas S. Lewis. "Effect of barley flour on the physical and sensory characteristics of chocolate chip cookies," Journal of Food Science and Technology, 48(5): 569-576. (2011)

[25] Uysal, H. Bilgiçli, N. Elgün, A. İbanoğlu, Ş. Herken, E.N. and Demir, M.K. " Effect of dietary fibre and xylanase enzyme addition on the selected properties of wire-cut cookies," Journal of Food Engineering, 78: 1074-1078 (2007)

[26] Kumbhare, V. and Bhargava, A. "Effect of processing on nutritional value of central Indian bamboo shoots," Journal of Food Science and Technology-Mysore, 44(1): 29-31 (2007)

[27] Younas, A. Bhatti, M.S. Ahmed, A. and Randhawa, M.A. "Effect of rice bran supplementation on cookie baking quality," Pakistan Journal ofAgriculture Sciences, 48(2): 129-134. (2011)

[28] Sudha, M.L. Vetrimani, R. and Leelavathi, K. "Influence of fibre from different cereals on the rheological characteristics of wheat flour dough and on biscuit quality" Food Chemistry, 100(4): 1365-1370 (2007)

[29] Sharma, H. and Chauhan, G. "Effects of stabilized rice bran: fenugreek blends on the quality of breads and cookies,"Journal of food science and technology, 39(3): 225-233 (2002) 